\title{
Spontaneous Disappearance of an Intracranial Aneurysm After Subarachnoid Hemorrhage
}

\author{
Mark G. Hamilton and Oliver N.R. Dold
}

\begin{abstract}
Spontaneous disappearance of an intracranial aneurysm after subarachnoid hemorrhage is an uncommon event and usually associated with severe cerebral vasospasm, giant aneurysms or the use of antifibrinolytics. We present a young woman who suffered a grade 5 subarachnoid hemorrhage with severe vasospasm caused by a small anterior communicating artery aneurysm. The patient underwent a slow recovery and two years later requested surgery. Angiography demonstrated complete disappearance of the aneurysm. The neurosurgeon should be aware that spontaneous thrombosis of cerebral aneurysms can occur and ensure that angiography is repeated when surgery is significantly delayed.
\end{abstract}

\begin{abstract}
RÉSUMÉ: Disparition spontanée d'un anévrisme intracrânien après une hémorragie sous-arachnoïdienne. La disparition spontanée d'anévrismes intracrâniens après une hémorragie sous-arachnoïdienne est inusitée et habituellement associée à un vasospasme cérébral sévère, des anévrismes géants ou l'utilisation de substances antifibrinolytiques. Nous présentons le cas d'une jeune femme qui a subi une hémorragie sous-arachnoïdienne de grade 5 avec un vasospasme sévère causé pas un petit anévrisme de l'artère communicante antérieure. La patiente a eu une récupération lente et deux ans plus tard a demandé une chirurgie. L'angiographie a démontré une disparition complète de l'anévrysme. Le neurochirurgien devrait savoir que la thrombose spontanée d'anévrismes cérébraux peut survenir et s'assurer que l'angiographie est répétée quand la chirurgie est retardée de façon significative.
\end{abstract}

Can. J. Neurol. Sci. 1992; 19:389-39I

Individual case reports and small patient series have described both incomplete and complete disappearance of intracranial aneurysms. ${ }^{1}$ The incidence of this particular phenomenon in clinical practice is extremely uncommon, if not rare.

In the following case we present angiographic evidence of spontaneous disappearance of an aneurysm following subarachnoid hemorrhage (SAH) and discuss its clinical significance.

\section{Clinical History}

A twenty-nine-year-old woman presented in January 1988, eight days after a lumbar puncture had proven subarachnoid hemorrhage. She had a Hunt \& Hess clinical grade $5 .{ }^{2}$ Her initial Fischer CT grade is unknown. ${ }^{3}$

Angiography identified a $5 \mathrm{~mm}$ aneurysm originating at the anterior communicating artery (Figure 1). Her early clinical course was complicated by severe vasospasm with resultant cerebral infarction (Figure 2). No antifibrinolytic agents were used. Given her poor condition, clipping of the aneurysm was not done. The patient was left severely quadriparetic, dysphasic and congitively impaired.

Approximately twenty-four months of rehabilitation treatment resulted in a remarkable recovery. She now has a near normal "bedside" cognitive function evaluation and can walk with assistance. The patient requested surgical treatment of her aneurysm. Follow-up angiography demonstrated that the anterior cerebral arteries and anterior communicating artery were patent, however, no residual aneurysm was identified despite multiple injections and views (Figure 3). Spontaneous thrombosis of the aneurysm was diagnosed.

\section{Discussion}

Spontaneous thrombosis of an intracranial aneurysm has been described in various autopsy series to occur in $9 \%$ to $13 \%$ of cases. ${ }^{4-6}$ One of the earliest autopsy descriptions was by Bramwell in $1887 .^{7}$

There are a number of theories concerning pathogenesis of spontaneous thrombosis. Most involve some aspect of Virchow's triad for vessel thrombosis: stasis, hypercoagulability or endothelial injury. Cerebral vasospasm, systemic hypotension, local damage to the arterial wall due to aneurysmal rupture and antifibrinolytic agents have been implicated. ${ }^{14.8 .9}$ The relationship between the size of the aneurysmal neck and the volume of the aneurysmal sac has also been suggested as a pathogenic factor: a narrow neck will facilitate thrombosis. ${ }^{10}$ Using a dog aortic trifurcation aneurysm model, Roach ${ }^{11}$ reported

From the Department of Clinical Neurosciences, Division of Neurosurgery, Calgary General Hospital

Received October 28, 1991. Accepted in final form January 27, 1992.

Reprint requests to: Mark G. Hamilton, MDCM, c/o Editorial Office, Barrow Neurological Institute, 1350 West Thomas Road, Phoenix, Arizona, U.S.A., 85013 


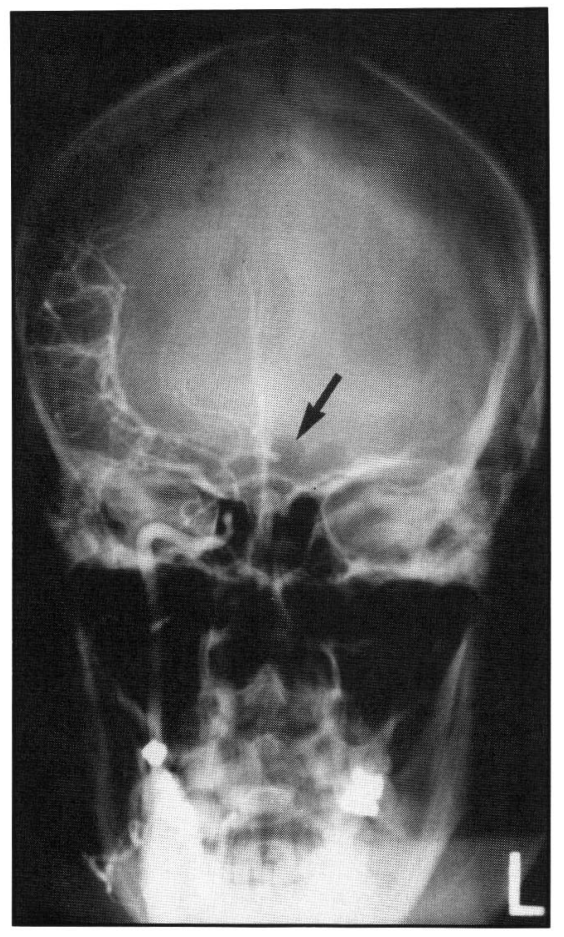

A

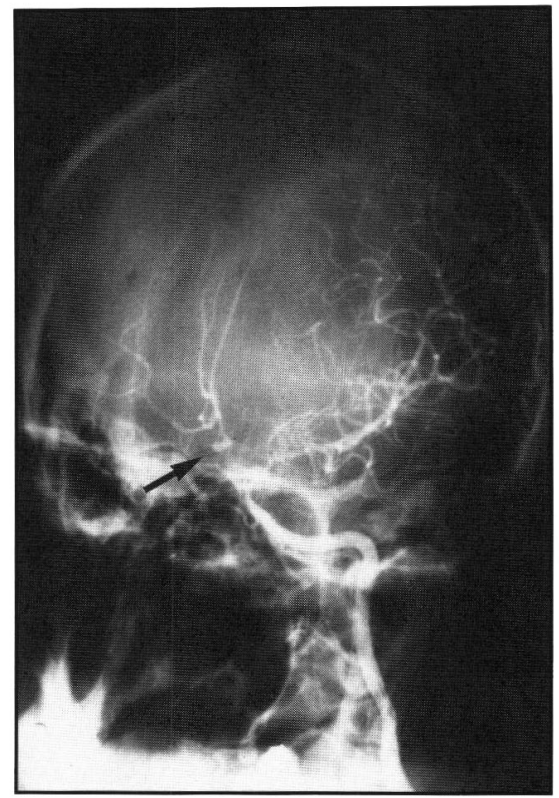

B

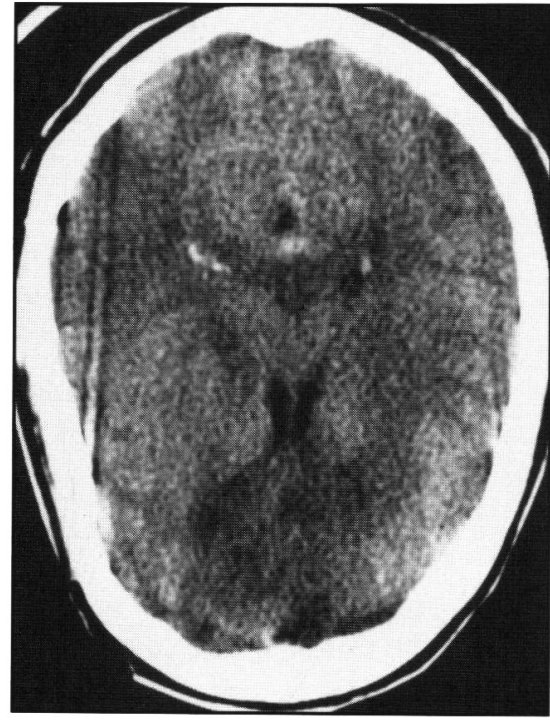

Figure $2-C T$ scan head (January 1988, eight days after $S A H$ ) demonstrating early diffuse infarction.

that thrombosis occurred within the aneurysmal sac when the distal wall of the aneurysm was more than $2-2.5$ diameters of the supplying artery from the mouth of the aneurysm. This feature has special implications for the spontaneous thrombosis of giant aneurysms. The pathogenesis of spontaneous aneurysmal thrombosis is more than likely a multifactorial phenomenon.

The true frequency of spontaneous thrombosis of intracranial aneurysms after SAH is unknown. It was suggested by Dandy, in 1945, that perhaps as many as $15 \%$ of patients with subarachnoid hemorrhage underwent spontaneous thrombosis and there- fore cure ${ }^{12}$ However, Pool and Potts found that only 3\% of nonsurgically treated aneurysms failed to visualize on subsequent angiography. ${ }^{13}$ In addition, most of the cases reported in the literature involved patients with giant aneurysms or patients treated with antifibrinolytic agents. ${ }^{1.8 .14 .15}$ The true clinical incidence of this event is extremely uncommon, if not rare.

In 1974, Spetzler, et al., described a patient with SAH and a left frontopolar artery aneurysm that initially was present, disappeared then reappeared twenty-one days later. ${ }^{16}$ This patient had severe vasospasm and had been treated with an antifibrinolytic agent. They raised the important question concerning what constitutes a "spontaneous cure" and encouraged caution in accepting angiographic occlusion of a recently ruptured aneurysm. Dávila, et al., in 1984, suggested that spontaneous cure could be described only if three conditions existed: "a good neurological outcome; disappearance of the aneurysm with patency of the parent artery and without spasm demonstrated in a follow-up angiography performed at least three months after the SAH; and no cerebral infarctions on CT scan". ${ }^{17}$ Therefore, a patient with a diagnosis of spontaneous thrombosis of an intracranial aneurysm needs follow-up angiography at least 3 months after the SAH has occurred.

The patient, in this report, has a complete occlusion of her aneurysm, with patency of all cerebral vessels confirmed by angiography done twenty-four months after her subarachnoid hemorrhage. Her severe vasospasm, complicating her SAH, likely played a very significant role in the thrombosis of her aneurysm. Her CT scan confirms cerebral infarction. Her clinical outcome, is consistent with a moderate disability classification on the Glasgow outcome scale. ${ }^{18}$ Thus, while she has an angiographically occluded aneurysm, her clinical course does not qualify her as a spontaneous cure as defined by Dávila. ${ }^{17}$ Given the extended period between subarachnoid hemorrhage and the most recent angiogram ( 2 years), no further treatment or investigation is contemplated for this patient. 


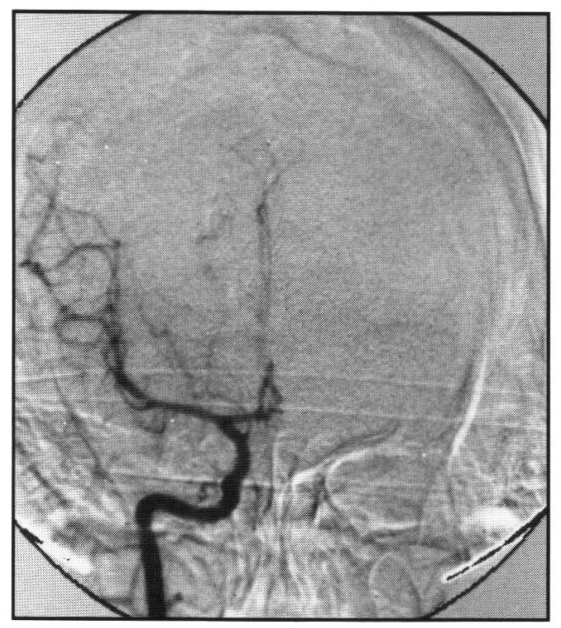

A

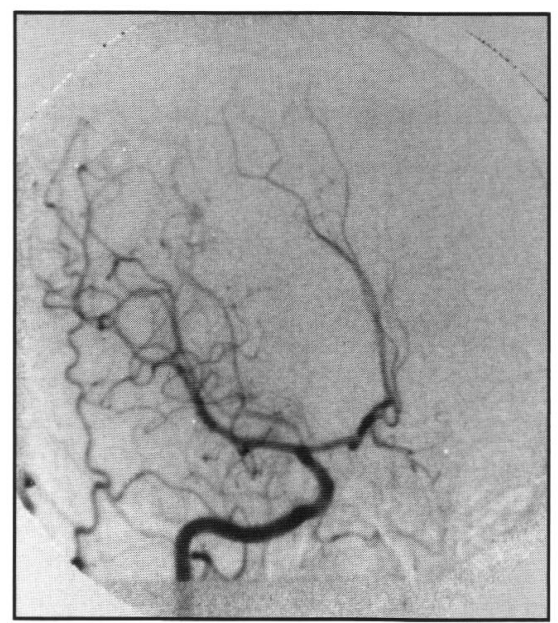

B

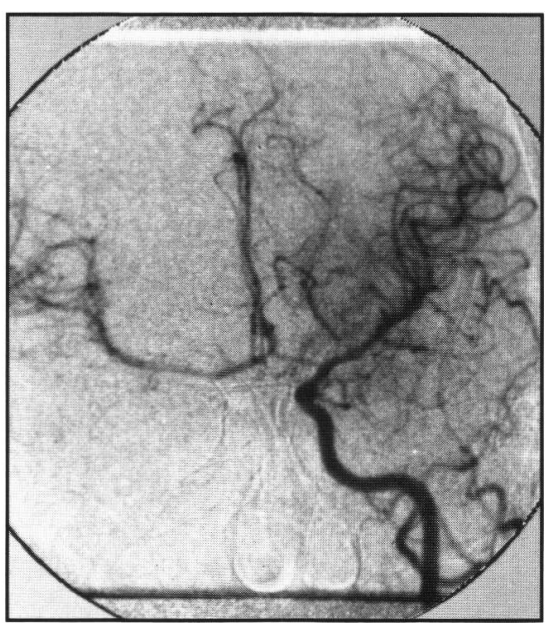

C

Figure 3-Cerebral Angiogram February 1990. (3A) AP - Right Carotid injection. (3B) Oblique - Right Carotid injection. (3C) AP - Left Carotid injection (Cross Compression). Both anterior cerebral arteries and the anterior communicating artery are patent but no aneurysm is identified. No vessel spasm is present.

This patient's case illustrates the important of repeating cerebral angiography if surgical clipping of an aneurysm is planned at a time significantly remote from the ictus. While we agree that spontaneous thrombosis is very uncommon, identifying its occurrence in this type of situation will prevent an unnecessary operation.

\section{REFERENCES}

1. Weir B. Aneurysms affecting the nervous system. Baltimore, Williams and Wilkins 1987: 219-223.

2. Hunt WE, Hess RM. Surgical risk as related to time of intervention in the repair of intracranial aneurysms. J Neurosurg 1968; 28 : 14-19.

3. Fischer CM, Kistler JP, Davis JM. Relation of cerebral vasospasm to subarachnoid hemorrhage visualized by computed tomographic scanning. J Neurosurg 1980; 6: 1-9.

4. Edner G, Forster DMC, Steiner L, Bergvall U. Spontaneous healing of intracranial aneurysms after subarachnoid hemorrhage. Case report. J Neurosurg 1978; 48: 450-454.

5. Fodstad $\mathrm{H}$, Lilequist $\mathrm{B}$, Schannong $\mathrm{M}$, Thulm $\mathrm{CA}$. Tranexamic acid in the preoperative management of ruptured intracranial aneurysms. Surg Neurol 1978; 10: 9-15.

6. Housepain EM, Pool JL. A systemic analysis of intracranial aneurysms from the autopsy file of the Presbyterian Hospital 1914 to 1956. J Neuropathol Exp Neurol 1958; 17: 409-423.

7. Bramwell B. Two enormous intracranial aneurysms. Edinburgh Med J 1887; 32: 911-922.
8. Fodstad H, Liliequest B. Spontaneous thrombosis of ruptured intracranial aneurysms during treatment with tranexamic acid (AMCA): report of three cases. Acta Neurochir (Wien) 1979; 49: 129-144.

9. Spallone A, Peresedov V, Kandel E. Spontaneous cure of ruptured intracranial arterial aneurysms. Surg Neurol 1981; 16: 367-370.

10. Black SPW, German WJ. Observations on the relationship between the volume and the size of the orifice of experimental aneurysms. J Neurosurg 1960; 17: 984-990.

11. Roach MR. A model study of why some intracranial aneurysms thrombose but others rupture. Stroke 1978; 9: 583-587.

12. Dandy WE. Intracranial arterial aneurysms. New York, Comstock Publishing 1944; 4: 1-22.

13. Pool JL, Potts DG. Aneurysms and anteriovenous anomalies of the brain. New York, Harper \& Row 1965.

14. Carlson DH, Thomson D. Spontaneous thrombosis of a giant cerebral aneurysm in five days. Report of a case. Neurology 1976; 26: 334-336.

15. Whittle JR, Dorsch NW, Besser M. Spontaneous thrombosis in giant intracranial aneurysms. J Neurol Neurosurg Psychiatry 1982; 45: 1040-1047.

16. Spetzler RF, Winestock D, Newton HT, Boldrey EB. Disappearance and reappearance of cerebral aneurysm in serial arteriograms. Case report. J Neurosurg 1974; 41: 508-510.

17. Dávila S, Oliver B, Molet J, Bartumeus F. Spontaneous thrombosis of an intracranial aneurysm. Surg Neurol $1984 ; 22: 29-32$.

18. Jennett $B$, Bond $M$. Assessment of outcome after severe brain damage. A practical scale. Lancet 1975; 1: 480-484. 